\title{
Caracterização e Estudo das Propriedades Físicas, Químicas e Mecânicas das Argilas Cauliníticas da Região Nordeste do Estado do Pará
}

\author{
Characterization and Physical, Chemical \\ and Mechanical Properties of the Kaolinitic \\ Clays of the Northeast Region of Pará State
}

Lêda de Azevedo Racanelli ${ }^{1}$, Verônica Scarpini Cândido ${ }^{1}$, José Antônio da Silva Souza ${ }^{1}$, Dilson Nazareno Cardoso ${ }^{1}$,

\footnotetext{
${ }^{1}$ UFPA/ITEC/PRODERNA - Programa de Pós-Graduação em Engenharia de Recursos Naturais da Amazônia, Belém, PA, Brasil.

e-mail: ledaazevedo@ufpa.br, scarpini@ufpa.br, jass@ufpa.br,dnpcardoso@gmail.com
}

\begin{abstract}
RESUMO
Neste trabalho o objetivo foi caracterizar e estudar o comportamento tecnológico de dois tipos de argilas oriundas da região de São Miguel do Guamá-Pará (norte do Brasil) a partir de formulação argilosa. Foram testadas formulações compostas pela mistura e sem mistura de Argila Forte e Fraca. As matérias-primas foram submetidas a ensaios de DRX, FRX e MEV e peneiramento e sedimentação. Elaborou-se corpos de prova dos quais foram prensados uniaxialmente em matriz retangular metálica. As propriedades físicas e tecnológicas determinadas foram: Absorção de água, porosidade aparente, massa específica aparente, retração linear de queima e resistência à flexão em três pontos. A microestrutura das cerâmicas foi avaliada por MEV e DRX. Os resultados indicaram que as argilas possuem características favoráveis para produção de blocos de vedação, mostrando que a melhor composição ficou com a mistura de $70 \%$ de argila fraca mais $30 \%$ de argila forte (M4).
\end{abstract}

Palavras-chave: argilas, cerâmica vermelha, caracterização, propriedades mecânicas.

\section{ABSTRACT}

This work was developed to study the behavior of two types of clays from São Miguel do Guamá-Pará region (northern Brazil) from a series of clay. Mixed and unmixed formulations of Strong and Weak Clay were tested. The raw materials were subjected to XRD, XFR, SEM and screening and sedimentation tests. It was elaborated the test components were pressed uniaxially in rectangular metal matrix. Physical and systematic properties were: Water absorption, apparent porosity, apparent mass production, linear firing shrinkage and flexural strength at three points. The microstructure of the ceramics was evaluated by SEM and XRD. The values presented as clays have favorable characteristics for the production of sealing blocks, showing that the best combination was a $30 \%$ strong clay (M4) mixture.

Keywords: clay, red clay, Description, mechanical properties.

\section{INTRODUÇÃO}

A argila é a matéria-prima utilizada para fabricação de diversos produtos como blocos, tijolos, telhas, tubos, ladrilhos, elementos vazados e outros. As razões para isso se devem à presença de plasticidade no material; resistência mecânica após queima adequada; aplicação de técnicas de processamento simples e pela disponibilidade de matéria-prima [1].

O processo de fabricação de cerâmica é complexo e necessita ser analisado sempre de forma global, envolvendo todas as etapas processo. No geral, o processamento é composto por uma sequência de etapas integradas que vai desde a escolha da matéria-prima até a queima da peça, porém, sendo quatro as etapas 
principais: a preparação da massa, conformação, secagem e queima, respectivamente. É reportado [2,3] que todas essas etapas devem ou pelo menos deveriam ser analisadas e otimizadas de forma conjunta, para se obter a microestrutura necessária e, consequentemente, as propriedades mecânicas desejadas.

Sobre a comercialização de peças, deve-se frisar que para a fabricação, utiliza-se de matéria-prima argilosa e o conhecimento das características dessas matérias-primas e de sua relação com os parâmetros de processamento na qualidade dos produtos cerâmicos são de suma importância [3]. Referente às cerâmicas tradicionais, existem dois tipos utilizados nos processos de fabricação, as denominadas de argilas plásticas ou fortes e as argilas não-plásticas ou magras como são comumente conhecidas. Com a utilização desses dois tipos de argilas para produção é importante que seja aprofundada a pesquisa na tecnologia cerâmica a fim de se ter os subsídios para produzir peças com melhor qualidade, usando matérias-primas aparentemente diferentes.

O estado do Pará possui o maior número de empresas fabricantes de cerâmicas tradicionais da região Norte do país, distribuídas em aproximadamente 07 Microrregiões e que são significativas do ponto de vista econômico. Até o ano de 2014 o estado contava com aproximadamente 200 empresas já cadastradas, gerando cerca de 15 mil empregos diretos e 40 mil indiretos [4].

Ainda se tratando da região norte do Brasil, o município de São Miguel do Guamá, localizado na região nordeste paraense, é considerado o maior polo de produção de cerâmica vermelha capaz de gerar mais de três mil empregos diretos. Fabricante de aproximadamente cinquenta milhões de peças cerâmicas por mês, o município é responsável por atender a demanda do próprio estado e outra pequena parte do estado do Maranhão $[4,5]$.

As peças comercializadas dividem-se, na sua grande maioria, em blocos de vedação (tijolos) e telhas. Essa grande produção é o que movimenta a economia da cidade [5].

Embora a cidade seja uma referência no segmento de produção de cerâmica vermelha, ainda poucos trabalhos são observados somente com a formulação de massa argilosa dessa região. Pouco se vê na literatura um panorama sobre as características e propriedades físicas, químicas e mecânicas dessas argilas. Nesse sentido, tem-se disponível apenas o trabalho $[6,7,8]$ explorando algumas das características das argilas da região.

Então, notadamente, todas estas pesquisas encontradas que estudam essas argilas do município, apresentaram resultados das matérias-primas incorporadas a outros resíduos. Dessa forma, pode-se dizer que este trabalho tem como objetivo caracterizar e estudar o comportamento físico, químico e mecânico dos dois tipos de argilas oriundas do município de São Miguel do Guamá a partir de formulação argilosa utilizada para produção dos blocos de vedação.

\section{MATERIAIS E MÉTODOS}

\subsection{Materiais}

Para a realização desse estudo foram utilizados dois tipos de argilas, uma plástica e uma não-plástica comumente denominadas de forte e fraca, respectivamente, oriundas do município de São Miguel do GuamáPA. A Figura 1 apresenta as argilas estudadas.

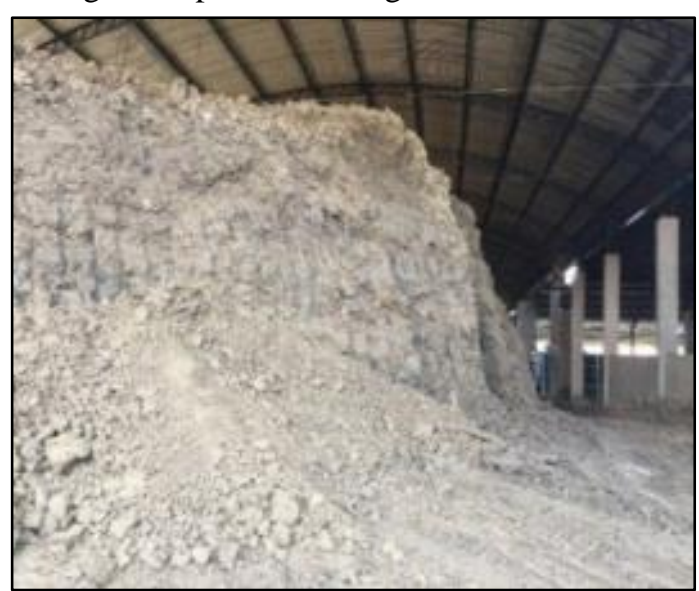

(a)

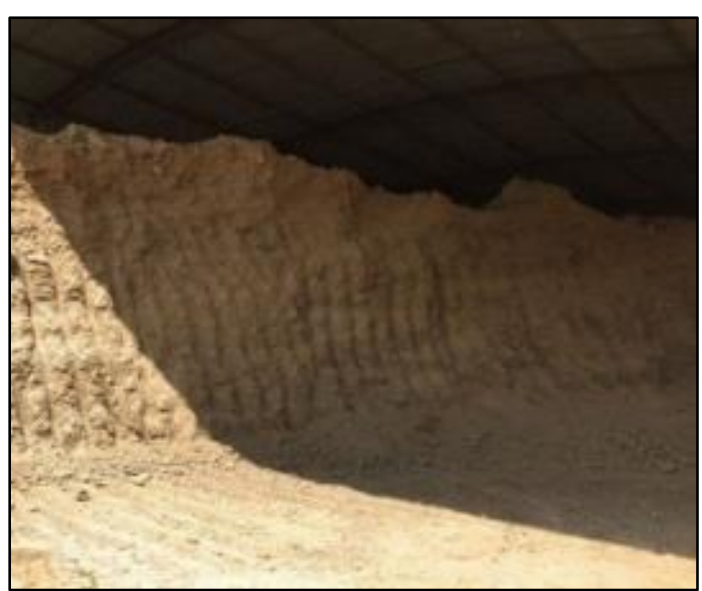

(b)

Figura 1: Argila Forte (a) e Argila Fraca (b). 


\subsection{Métodos}

\subsubsection{Preparo das argilas}

Após a coleta, as argilas foram encaminhadas ao Laboratório Beneficiamento de Materiais da Faculdade de Engenharia Química da Universidade Federal do Pará (UFPA) e secas em estufa de modelo DIMATE, à temperatura de $110{ }^{\circ} \mathrm{C}$ durante $24 \mathrm{~h}$. Após essa etapa o material foi conduzido para o moinho de bolas de modelo Work Index série 005, onde foi realizada a etapa de desagregação, por um período de 30 minutos. Após esta etapa as massas preparadas foram umedecidas com spray de água, até $10 \%$, de modo a possibilitar a conformação por prensagem dos 120 corpos de prova. A Tabela 1 apresenta as formulações estudadas.

Tabela 1: Proporção das formulações

\begin{tabular}{ccc}
\hline Formulações & \multicolumn{2}{c}{$\begin{array}{c}\text { Matérias-primas (\% em peso) } \\
\text { Argila Forte }\end{array}$} \\
\hline M1 & 100 & - \\
M2 & - & 100 \\
M3 & 50 & 50 \\
M4 & 30 & 70 \\
\hline
\end{tabular}

As formulações escolhidas foram pensadas para uma produção desde a matéria-prima sem mistura dos dois tipos de argila até outras com variação em misturas entre si.

\subsubsection{Análise granulométrica}

A análise foi realizada para se verificar os diâmetros médios das partículas e para isso utilizou-se um equipamento laser Particle Sizer Analysette 22 Fritsch com software MaScontrol para a aquisição dos dados experimentais.

\subsubsection{Caracterizações}

A difração de raios X foi realizada em difratômetro da PANalytical, operando a $40 \mathrm{kV}$ e $40 \mathrm{~mA}$ e com um comprimento de onda $\lambda \mathrm{CuK} \alpha=1,54 \AA$. A amostra foi examinada em um intervalo de $2 \theta$ entre $4-70^{\circ}$, com um passo angular de $0,02^{\circ}$ e tempo por passo 30s. A identificação de fases foi feita usando o software HighScore.

A identificação dos componentes químicos deste estudo foi realizada em espectrofotômetro de fluorescência de raios X por energia dispersiva (EDX) em um espectrômetro Shimadzu, modelo EDX-700 e por fim, a análise morfológica das partículas foi feita utilizando microscópio eletrônico de varredura de bancada Hitachi Analytical TableTop (SEM TM3030).

\subsubsection{Preparo dos corpos de provas}

A partir dos dois tipos de argilas coletadas, elaboraram-se quatro formulações M1, M2, M3 e M4, já citadas no item 2.2.1.

As massas argilosas a serem conformadas foram umedecidas com $10 \%$ em massa de água, passadas novamente em moinho de bolas, peneiras e, posteriormente, acondicionadas em sacos plásticos por $24 \mathrm{~h}$.

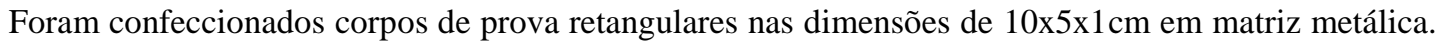
A prensagem uniaxial foi realizada em prensa hidráulica manual Karl Kolb (Scientific Technical Suplies) aplicando uma carga de aproximadamente 20MPa.

Após a etapa de conformação, os corpos de prova secaram à temperatura ambiente por 24 horas e, depois, em estufa da marca Ds Diagnóstica a $110^{\circ} \mathrm{C}$ até alcançarem peso constante. Após a etapa de secagem, os corpos de prova foram medidos com o auxílio de um paquímetro digital da marca Mitutoyo com precisão de $0,01 \mathrm{~mm}$ e pesado em balança de precisão da marca BEL com de precisão de $0,001 \mathrm{~g}$.

A queima dos corpos de prova foi realizada em três temperaturas de $\left(850,950\right.$ e $\left.1050^{\circ} \mathrm{C}\right)$ em forno tipo mufla da marca EDG, modelo 3P-S utilizando-se uma taxa de aquecimento constante de $2^{\circ} \mathrm{C} / \mathrm{min}$ e mantidos na temperatura patamar por $2 \mathrm{~h}$. $\mathrm{O}$ resfriamento se deu por convecção natural desligando-se o forno. A Figura 2 apresenta dos corpos de prova antes e após a etapa de queima. 


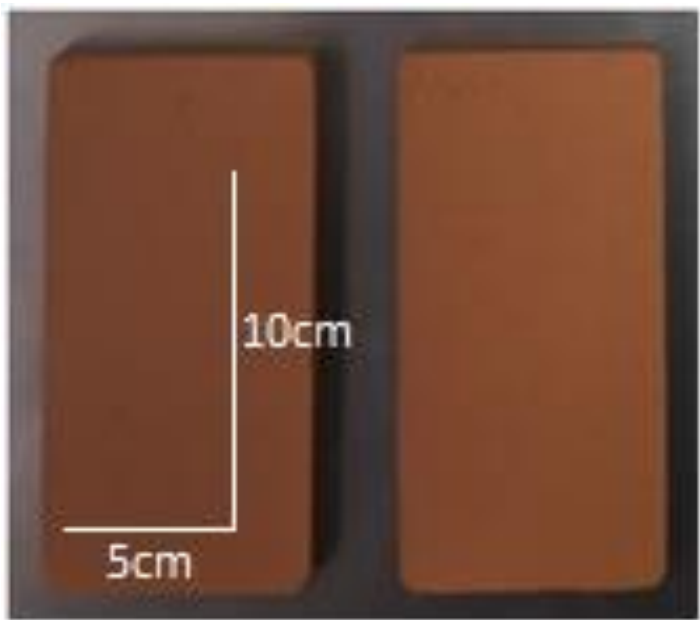

Figura 2: Corpo de prova com dimensões de $10 \times 5 \times 1 \mathrm{~cm}$.

\subsubsection{Análise Morfológica}

Realizada nos dois tipos de argila in natura e após a queima do material, foi avaliado a região de fratura dos corpos de provas em equipamento MEV de bancada (Hitachi Analytical TableTop, SEM TM3030).

\section{RESULTADOS E DISCUSSÕES}

\subsection{Analise granulométrica}

Nas argilas coletadas, nota-se que o teor de "fração argila" na Argila Forte é igual a 14,24\% e para a Argila Fraca é igual a 7,12\%. A fração "silte" compreende partículas com tamanho entre 0,002 e 0,02 mm e o percentual dessa fração na Argila Forte é igual à 45,94\% e para a Argila Fraca é igual a 47,68\%. A fração "areia" compreende partículas com tamanho superiores a $0,02 \mathrm{~mm}$ e o percentual dessa fração na Argila Forte é igual a 39,82\% e para a Argila Fraca é igual a 45,20\% conforme a Figura 3.

No intervalo menor que $0,002 \mathrm{~mm}$ a Argila Forte apresenta maior porcentagem desse diâmetro de partículas e como os argilominerais, responsáveis pela plasticidade, estão associados a este intervalo, a maior plasticidade dessa argila pode ser justificada quando comparada a Argila Fraca [1,9].

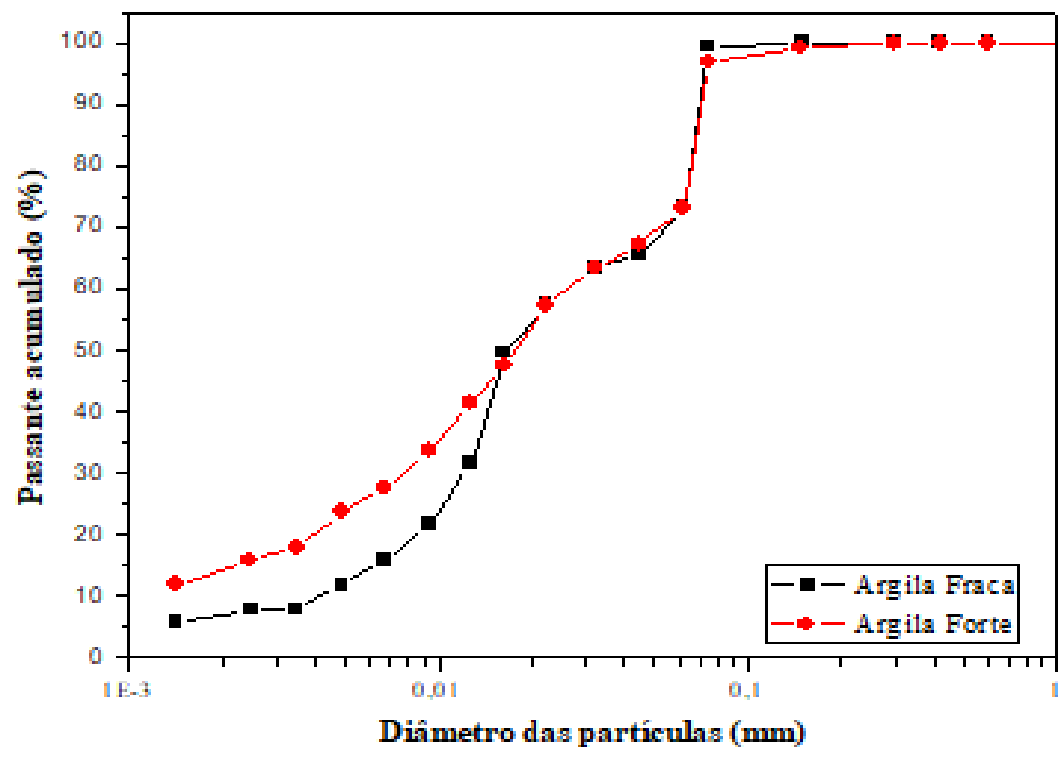

Figura 3: Diâmetro das partículas das Argilas Forte e Fraca.

\subsection{Espectrometria de fluorescência de raios $X$ por energia dispersiva (XRF/EDX)}

A Tabela 2 apresenta a composição química expressa em termos percentuais bem como a perda ao fogo (PF) das argilas coletadas. 
Tabela 2: Composição química das matérias-primas estudadas (\%).

\begin{tabular}{ccccccccc}
\hline \multicolumn{1}{c}{ Argila Forte } \\
Elemento & $\mathrm{SiO}_{2}$ & $\mathrm{Al}_{2} \mathrm{O}_{3}$ & $\mathrm{Fe}_{2} \mathrm{O}_{3}$ & $\mathrm{~K}_{2} \mathrm{O}$ & $\mathrm{TiO}_{2}$ & $\mathrm{CaO}$ & $\mathrm{MnO}$ & \\
Teor $(\%)$ & 59,03 & 26,75 & 9,09 & 3,31 & 1,80 & - & - & 12,19 \\
\hline \multicolumn{1}{c}{ Argila Fraca } \\
Elemento & $\mathrm{SiO}_{2}$ & $\mathrm{Al}_{2} \mathrm{O}_{3}$ & $\mathrm{Fe}_{2} \mathrm{O}_{3}$ & $\mathrm{~K}_{2} \mathrm{O}$ & $\mathrm{TiO}_{2}$ & $\mathrm{CaO}$ & $\mathrm{MnO}$ & \\
Teor $(\%)$ & 66,39 & 18,74 & 7,75 & 4,36 & 1,63 & 0,97 & 0,14 & 5,38 \\
\hline
\end{tabular}

Diante dos resultados da caracterização, verifica-se a similaridade da composição química entre as duas argilas estudadas, porém com percentuais de óxidos diferentes. A sílica e a alumina como óxidos predominantes, seguido do óxido de ferro $\left(\mathrm{Fe}_{2} \mathrm{O}_{3}\right)$ que acima de $4 \%$ contribui para coloração avermelhada dos aos blocos de vedação quando submetidas a um tratamento térmico [10]. É observada ainda a presença de $\mathrm{K}_{2} \mathrm{O}$, um óxido que pode favorecer a formação de fase líquida durante a etapa de queima.

Referente à PF das argilas estudadas, isso acontece devido à eliminação de água dos argilominerais, desidratação de hidróxidos e oxidação da matéria orgânica. E os resultados dessas perdas ao fogo obtidas nos dois tipos de argila, mostraram-se dentro da normalidade para fabricação de materiais cerâmicos que é abaixo de $13 \%$ [11].

\subsection{Difração de raios $X$ nas argilas in natura}

A Figura 4 apresenta o difratograma da Argila Fraca e Argila Forte. Foi mostrado [2] que as argilas da região de São Miguel do Guamá revelaram fases cristalinas também semelhantes às fases encontradas nas argilas utilizadas nesse estudo. O resultado mostra fases cristalinas presentes como a caulinita, quartzo, mica muscovita e anatásio.

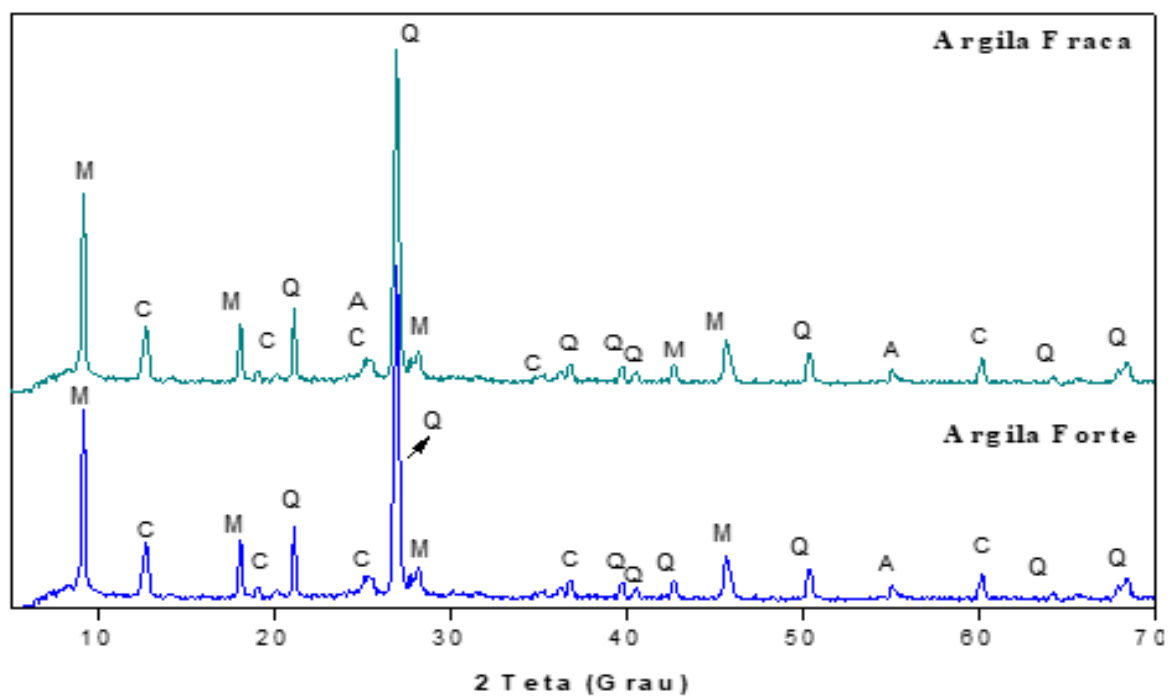

Figura 4: Difratograma de raios X da Argila Fraca e Argila Forte. M: Mica; C: Caulinita; Q: Quartzo e A: Anatásio.

Os picos predominantes são referentes à caulinita $\left(\mathrm{Al}_{2} \mathrm{O}_{3} \cdot 2 \mathrm{SiO}_{2} \cdot 2 \mathrm{H}_{2} \mathrm{O}\right)$ e ao quartzo $\left(\mathrm{SiO}_{2}\right)$. Os picos de quartzo (Q) são evidenciados por sua intensidade, isto é, devido ao alto grau de cristalinidade em relação à caulinita e não à sua concentração em si. Quanto ao quartzo presente na argila, é atuante como matéria-prima não-plástica e inerte durante a sinterização. Já o anatásio $\left(\mathrm{TiO}_{2}\right)$ cristaliza no sistema tetragonal, possuindo cor e brilho variáveis. A mica muscovita pode atuar como fundente já que em sua estrutura existe a presença de óxido alcalinos, por fim, a caulinita como sendo o argilomineral responsável pelo desenvolvimento da plasticidade da argila em mistura com a água [12].

\subsection{Microscopia Eletrônica de Varredura (MEV) das argilas in natura}

Na Figura 5 estão apresentadas as micrografias obtidas por MEV das matérias-primas. Nota-se que a Argila Forte (a) e Argila Fraca (b) apresenta pequenas partículas de morfologia pseudo-hexagonais associadas provavelmente a caulinita, argilomineral presente nas argilas [11]. 


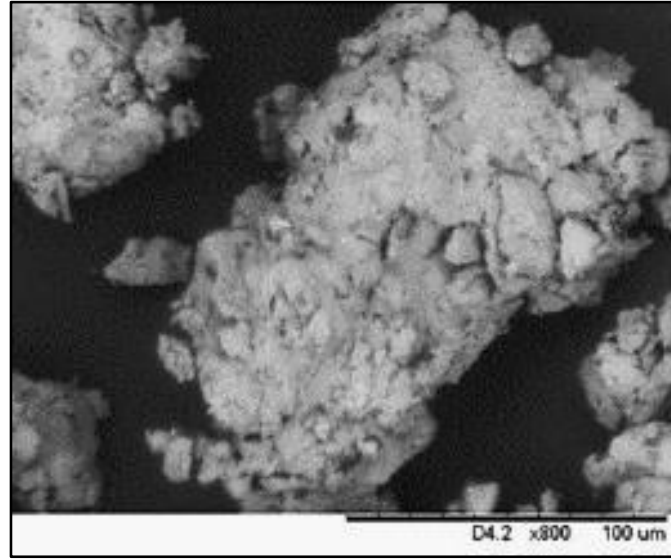

(a)

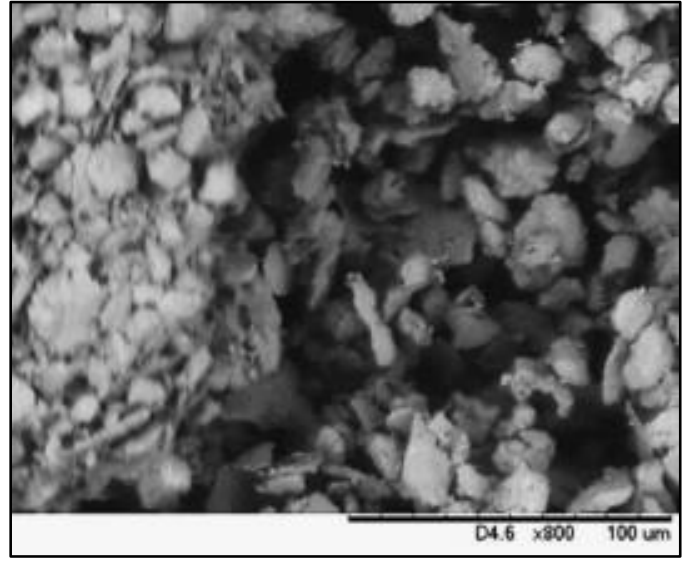

(b)

Figura 5: Microscopia Eletrônica de Varredura da Argila Forte (a) e Argila Fraca (b).

\subsection{Ensaios}

\subsubsection{Porosidade Aparente}

Foi mostrado [11] que as porosidades abaixo dos valores máximos de $35 \%$ para uma temperatura de $950^{\circ} \mathrm{C}$ podem ser considerados parâmetros aceitáveis para cerâmica vermelha. Como pode ser observado na Figura 6, os dados obtidos mostram que as peças de cerâmicas mais porosas estão concentradas nas duas primeiras temperaturas, ou seja, entre 850 e $950^{\circ} \mathrm{C}$. Isso acontece pelo não fechamento dos poros existentes nas peças. Por se tratar de argilas de características refratárias, o processo de sinterização nestas duas temperaturas não ocorre de forma tão eficiente, daí o melhor resultado obtido ter sido na temperatura maior $\left(1050^{\circ} \mathrm{C}\right)$.

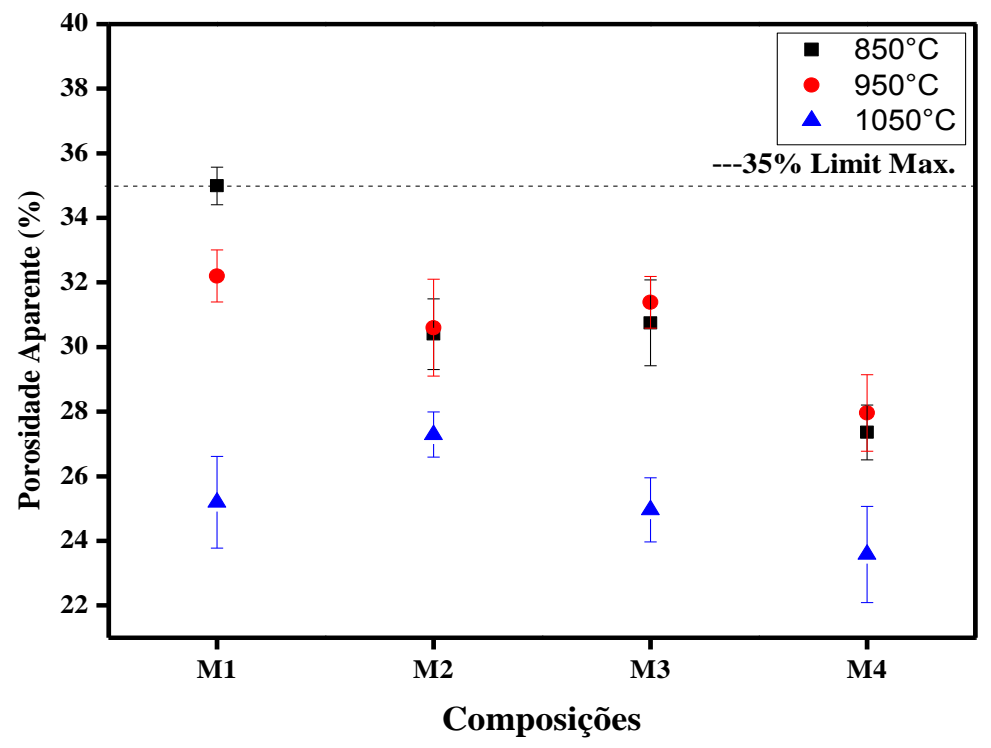

Figura 6: Porosidade das cerâmicas.

\subsubsection{Massa Específica Aparente (MEA)}

Reportado [9] que a massa específica aparente permitida para cerâmica vermelha é abaixo de $2,7 \mathrm{~g} / \mathrm{cm}^{3}$, sendo assim, os dados obtidos (Figura 7) revelam que todas as amostras estiveram dentro do valor estabelecido. Isso acontece devido a um melhor empacotamento das partículas durante a etapa de conformação contribuindo para o fechamento da porosidade aberta durante a sinterização. Esse fator pode corroborar para a melhoria das propriedades tecnológicas do produto acabado. 


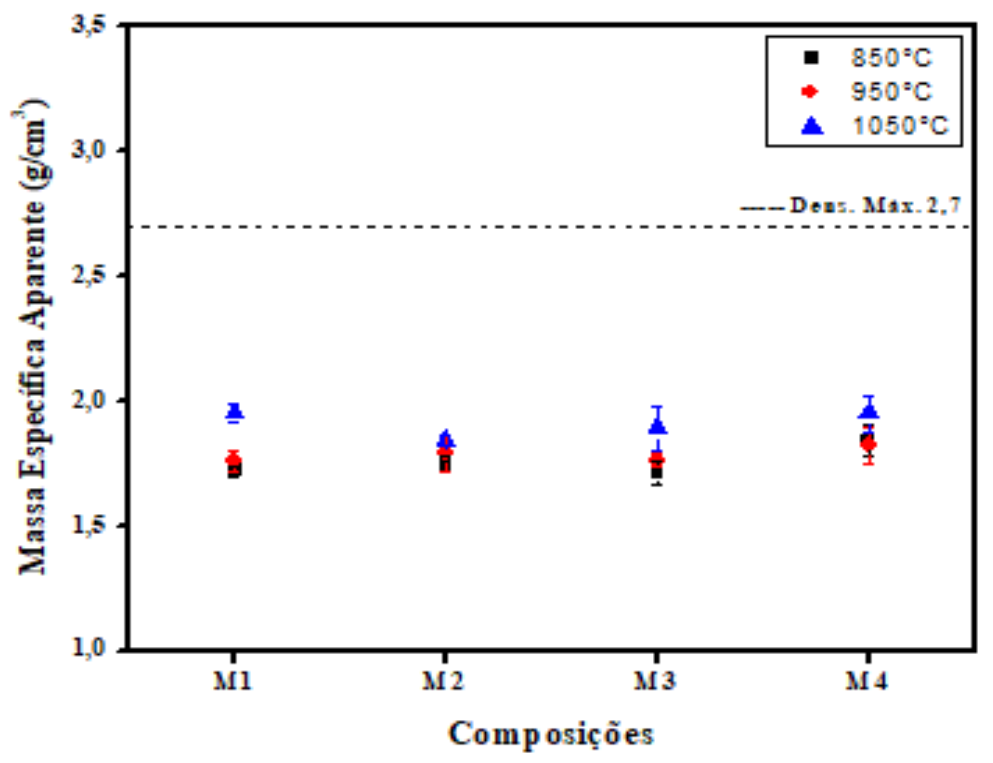

Figura 7: Massa Específica Aparente (MEA).

\subsubsection{Absorção de água}

A Figura 8 apresenta o comportamento da absorção de água das peças cerâmica queimadas. Observa-se que não houve índice de absorção de água superior a $22 \%$, ou seja, todos estão dentro do estabelecido pela norma [13]. No entanto, é importante frisar que a formulação $\mathrm{M} 1$ queimada em temperatura de $850^{\circ} \mathrm{C}$ foi a que apresentou o maior índice de absorção de água e isso acontece porque as reações de sinterização ainda estão em estágio inicial, com isso as transformações de fases, que começam a ocorrer nessa primeira temperatura, podem causar um aumento de porosidade, como observado nos resultados de porosidade aparente, culminando em aumento na absorção de água [14].

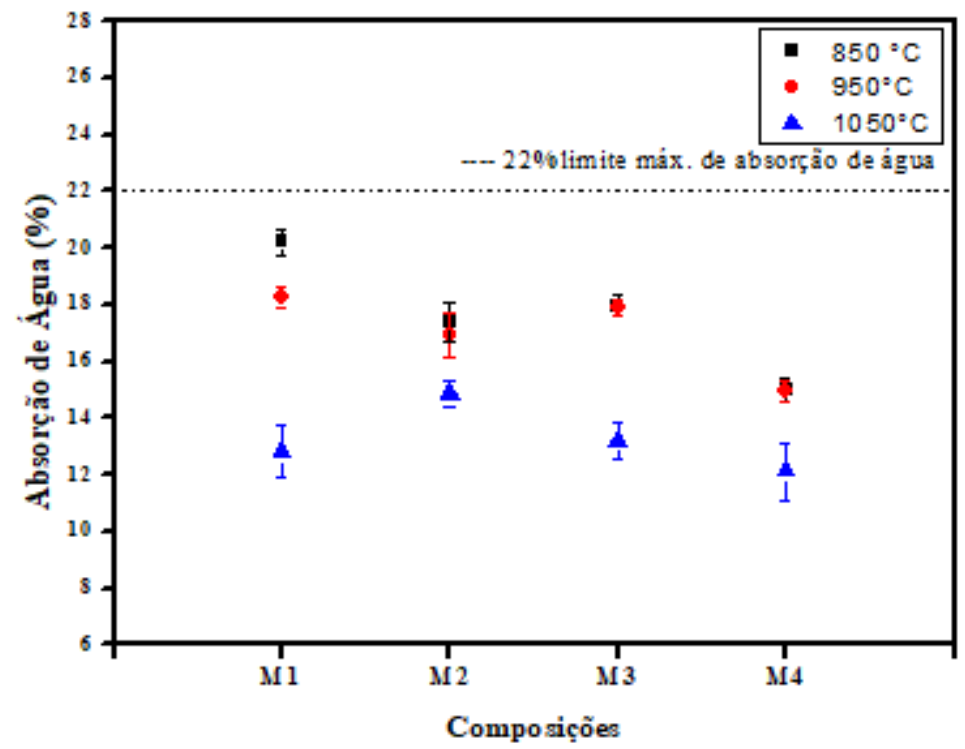

Figura 8: Absorção de água das cerâmicas.

\subsubsection{Retração Linear de Queima}

Foi mostrado [15] que o limite máximo de retração linear de peças queimadas deve ser inferior a 12\%. A Figura 9 apresenta a retração linear de queima das cerâmicas em função da temperatura estudada.Analisando todas as formulações, verifica-se que a maior retração ficou com composição de Argila Forte (M1), ou seja, representou o material de característica mais plástica do que M2, M3 e M4 na tempertura de $850^{\circ} \mathrm{C}$ Quando estas mesmas composições foram submetidas à temperatura de $950^{\circ} \mathrm{C}$ percebeu-se que houve uma leve retração, mas não significativo, dentro de um erro estatístico.Para a temperatura de $1050^{\circ} \mathrm{C}$ as retrações lineares se apresentaram com um comportamento elevado, ou seja, indicando que a partir dessa temperatura as peças começam a sofrer vitrificação, diminuindo assim a porosidade e promovendo aproximação das 
partículas[16].

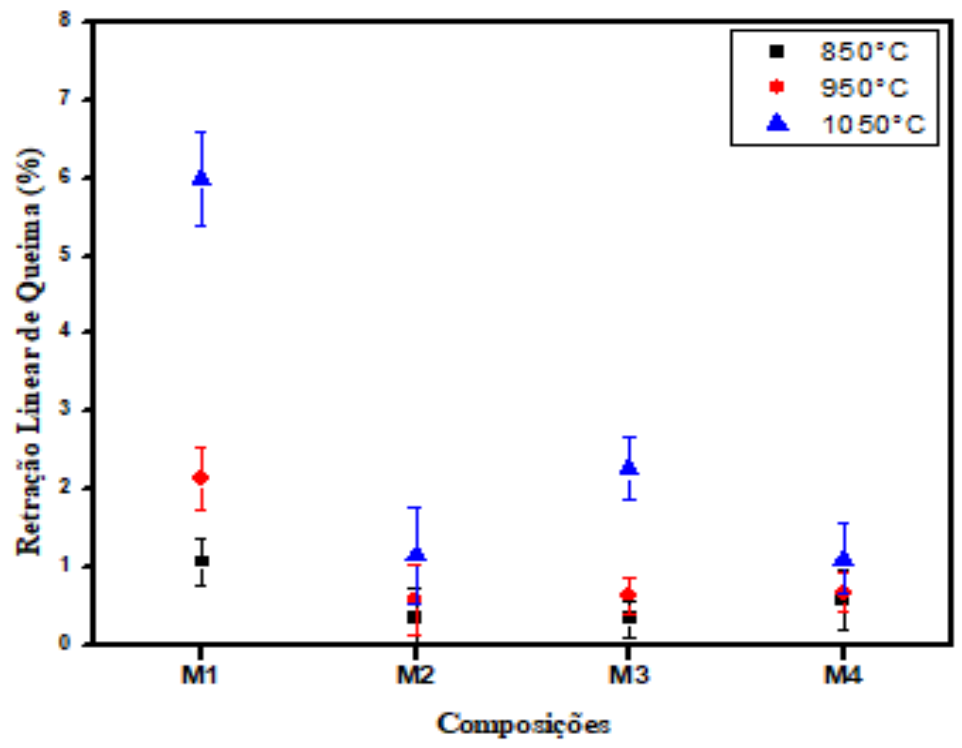

Figura 9: Retração linear pós queima das peças.

\subsubsection{Resistência à Flexão}

Reportado [17] que a tensão mínima de ruptura após a queima para blocos cerâmicos comerciais de vedação é de 1,5 MPa. A Figura 10 apresenta o comportamento de cada formulação quando submetidas ao ensaio de ruptura.

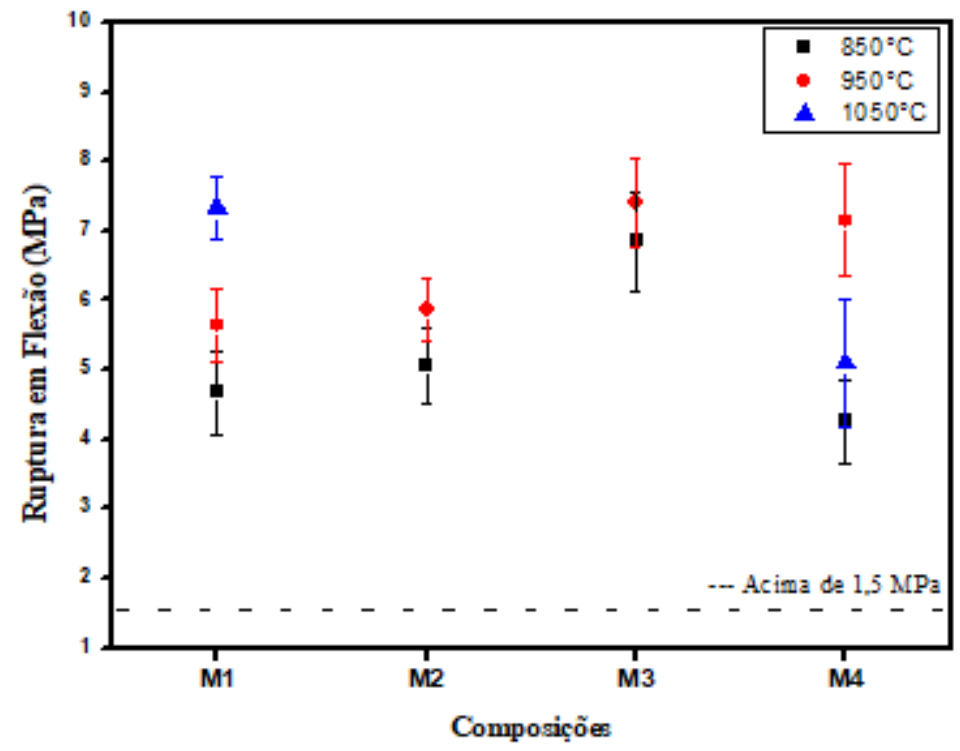

Figura 10: Resistência à flexão.

Todas as composições queimadas na temperatura de $850^{\circ} \mathrm{C}$ apresentaram valores acima de 1,5 $\mathrm{MPa}$ chegando a alcançar uma resistência de até $6,85 \mathrm{MPa}$. Entretanto, vale observar que ainda nesta temperatura, a composição de M4 é a que apresenta menor resistência e essa redução se deve pelas partículas mais grosseiras, constituídas na Argila Fraca , atuando como ponto de concentração de tensão [18].

Já na temperatura de $950^{\circ} \mathrm{C}$ houve um aumento da resistência e isso acontece pelo início da formação de fase líquida que diminui a porosidade do material contribuindo assim para uma melhor resistência [18]. Entretanto, vale ressaltar que as maiores resistências ficaram com as composições em que há mistura do material entre Argila Forte e Argila Fraca.

Observou-se que trabalhando na fabricação de tijolos sem mistura alguma, ou seja, apenas de M1 e M2 a resistência ficou menor, em torno de $5 \mathrm{MPa}$. E os valores obtidos dos testes, indicam que todas as composições queimadas nas três temperaturas podem ser indicadas para produção desses produtos. 


\subsection{Análise morfológica dos corpos de prova}

\subsubsection{Microscopia Eletrônica de Varredura (MEV)}

A Figura 11 apresenta as micrografias obtidas por MEV das regiões de fraturas das cerâmicas. Demonstrado [19] que as cerâmicas vermelhas queimadas em temperaturas inferiores a $970^{\circ} \mathrm{C}$ não apresentam uma consolidação estrutural eficiente, os resultados das fraturas estudadas confirmam que a $950^{\circ} \mathrm{C}$ obtem-se regiões com porosidade e rugosidade. Esta característica microestrutural da cerâmica está relacionada às características da argila caulinítica tais como o baixo teor de fundentes, teor de alumina e sílica e a elevada perda de massa durante a queima [20].

A Figura 12 apresenta as regiões das fraturas analisadas a temperatura de $1050^{\circ} \mathrm{C}$ e como pode-se verificar na temperatura maior, a região das fraturas demonstram-se menos rugosas e isso está intimamente ligado ao aumento da temperatura, pois os grãos tendem a coalescer, isto é, os grãos se unem e permitem a diminuição da presença dos poros culminando assim em um perfil de áreas mais lisas, grãos mais unidos e mais compactados [20].

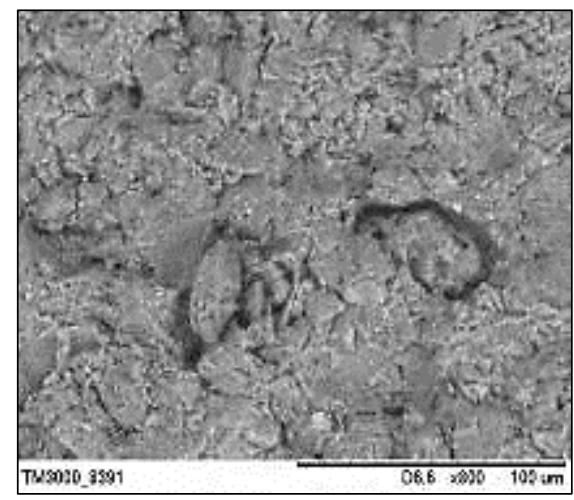

(a)

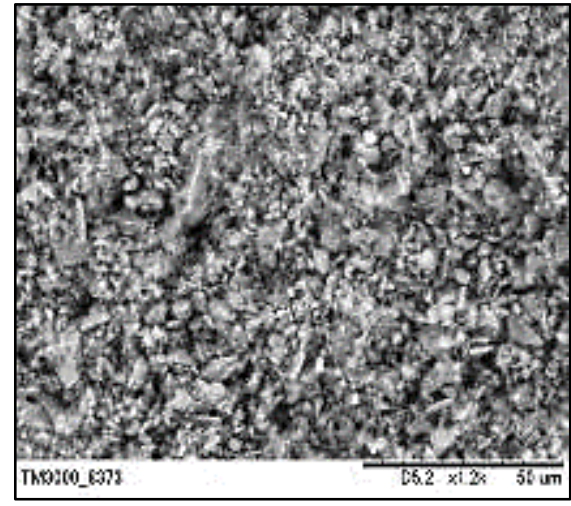

(c)

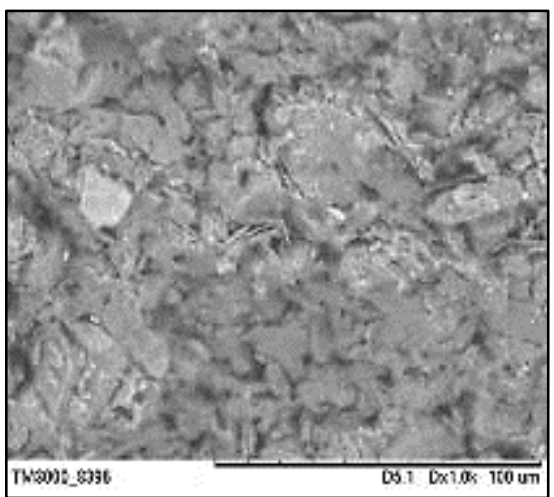

(b)

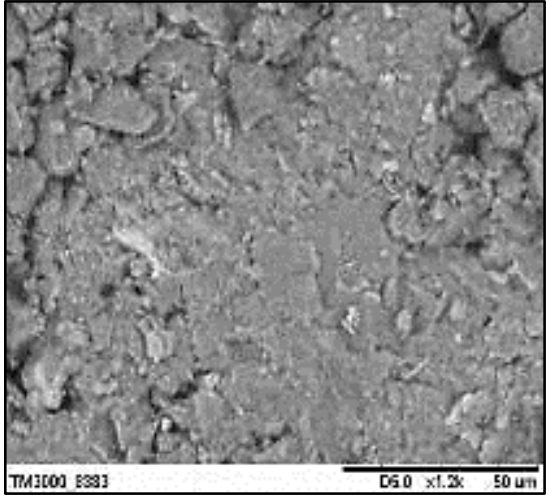

(d)

Figura 11: Micrografias de MEV das formulações M1 (a), M2 (b), M3 (c); M4 (d) a $950^{\circ} \mathrm{C}$.

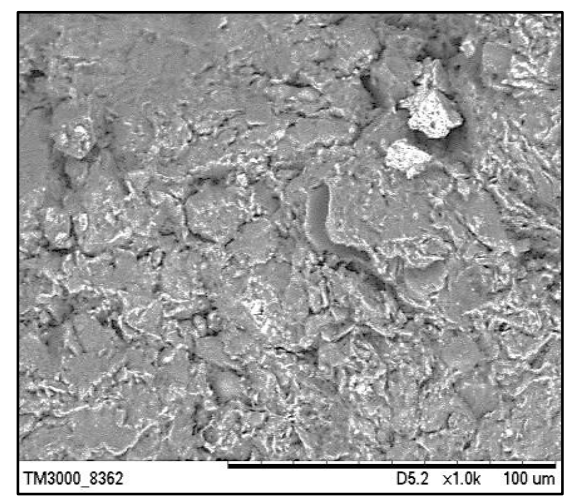

(a)

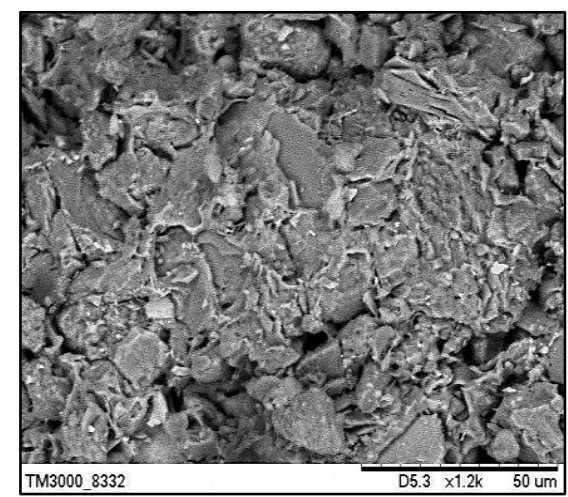

(b) 


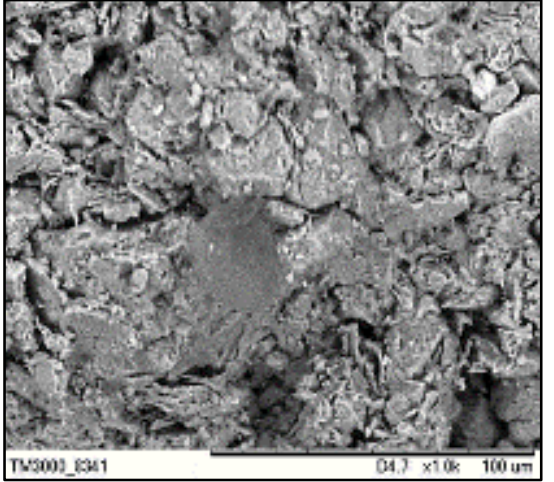

(c)

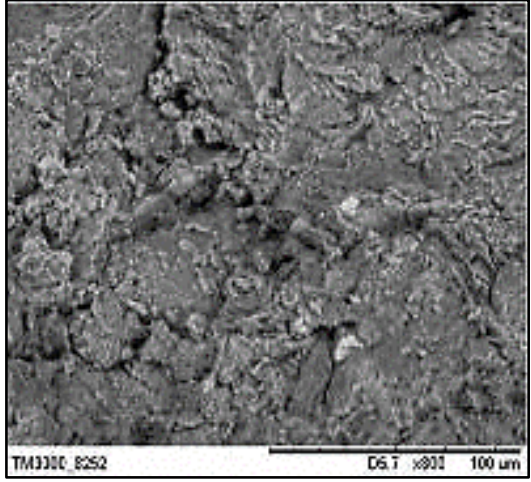

(d)

Figura 12: Micrografias de MEV das formulações M1 (a), M2 (b), M3 (c); M4 (d) a $1050^{\circ} \mathrm{C}$.

\section{CONCLUSÕES}

Os estudos realizados pelos autores, relacionados a Argila Forte e Argila Fraca, permitiram a disponibilização de dados científicos referente a caracterização e estudo das propriedades físicas, químicas e mecânicas desse material, bem como cada formulação se comporta mediante as exigências das normas regulamentadoras para comercialização.

- Os ensaios de caracterização das argilas in natura revelaram que elas são constituídas, sobretudo por caulinita, quartzo e mica muscovita. A Argila Forte (M1) apresenta como fases cristalinas predominantes a caulinita, quartzo, mica muscovita e anatásio;

- Argila Fraca (M2) apresentou fases cristalinas semelhantes às da Argila Forte (M1). Logo, a presença de caulinita revelou que as argilas usadas são cauliníticas e que podem apresentar boa plasticidade;

- As amostras de argilas possuem altos teores de sílicas associados a baixos teores de alumina que constituem um material característico para fabricação de cerâmica vermelha;

- A microscopia ótica (MO) das argilas in natura revelou uma morfologia pseudo-hexagonal associados as partículas ao argilomineral caulinita.

- Análise por MEV mostrou que temperaturas abaixo de $970^{\circ} \mathrm{C}$ não permitiram uma formação de fase liquida tão eficiente evidenciando uma granulometria grosseiras que podem atuar como concentradores de tensão;

- A formulação M2, M3 e M4 apresentara-se dentro dos parâmetros exigidos pela NBR;

- A formulação M1 foi a única que atingiu o limite da porosidade aparente estabelecido, e o maior índice de retração linear de queima.

- Sucintamente pôde-se provar que a massa cerâmica com mistura e sem mistura é tecnicamente viável quando se trata da resistência do material. Porém, provou-se que a mistura dos dois tipos de argila da região (M3 e M4) permite um melhor comportamento do material em todos os quesitos exigidos pela Normas Brasileiras (NBR);

- Diante dos resultados mecânicos, percebeu-se que todas as composições apresentaram-se, de certa forma, dentro dos parâmetros exigidos pela NBR. Porém, o melhor comportamento mecânico ficou com composição M4, daí esta ser a formulação ser a mais indicada para fabricação de blocos de vedação.

\section{AGRADECIMENTOS}

Os autores agradecem a CAPES, a empresa Menegalli e Universidade Federal do Pará pelo suporte fornecido a este trabalho.

\section{BIBLIOGRAFIA}

[1] ABAJO, M. P., Manual sobre Fabricacion de Baldosas Tejas y Ladrillos. Ed. Baralmar S.A., Espanha, p. $360,2000$.

[2] LIMA. J.J., "Estudo Geoeconômico e Tecnológico das Argilas utilizadas na Indústria Cerâmica dos Municípios de Irituia e São Miguel do Guamá”, Nordeste do Pará, Dissertação de M.Sc, UFPA, Belém, PA, Bra- 
sil, 2000.

[3] VIEIRA, C. M. F., HOLANDA, J. N. F., PINATTI, D. G, "Caracterização de massa cerâmica vermelha utilizada na fabricação de tijolos na região de Campos dos Goytacazes - RJ", Revista Cerâmica, v.46, n 297, pp. 14-17, 2002.

[4] ROCHA, A. L., BARTOLOMEU, A. O., BOTELHO, J. L., et al., "Industrial production of the ceramic in Sao Miguel do Guama and recent innovations adopted by segment nationwide", Revista IMED, v. 2, n 1 , pp.01-09, ISSN 2318-1109, 2013.

[5] CORDOVIL, G.V. "Pólo cerâmico e dinâmica territorial do desenvolvimento em São Miguel do Guamá PA", Desenvolvimento Regional em debate, v. 4, n 1, p. 40-62, 2014.

[6] LIMA. J.J. Estudo Geoeconômico e Tecnológico das Argilas utilizadas na Indústria Cerâmica dos Municípios de Irituia e São Miguel do Guamá, Nordeste do Pará, 2000.

[7] MACÊDO, E. N., SOUZA, J. A. S. "Relatório Técnico do Projeto de Pesquisa: Desenvolvimento de Tecnologia com a Utilização de Resíduos da Indústria Mineral para Melhoria da Qualidade de Produtos de Cerâmica Vermelha Utilizados na Indústria de Construção Civil e no Artesanato do Estado do Pará”., Universidade Federal do Pará, Belém, PA, Brasil. 2004.

[8] BETINI, D. G. "Inovação na Tecnologia de Produtos de Cerâmica Vermelha com Uso de Chamote em São Miguel do Guamá”, Dissertação de M.Sc, UFPA, Belém, PA. Brasil, 2007.

[9] SANTOS, P. S. Ciência e Tecnologia de Argilas., v. 2, Edgard Blücher LTDA, 1989.

[10] SÁNCHEZ, E., GARCÍA, J., SANZ,V., et al., "Critérios de Seleción de Matérias primas para La Fabricaión de Pavimentos y Revestimientos Cerâmicos", Céran. Información, v. 157, pp. 13-21, 1990.

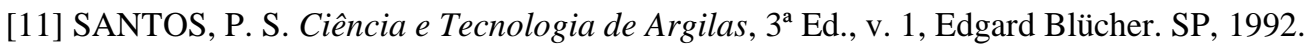

[12] RIBEIRO, M. M., "Material particulado de planta de sinterização de usina siderúrgica integrada em composição de massa de cerâmica vermelha", Tese de Doutorado, Universidade Estadual do Norte Fluminense, Campos dos Goytacazes, RJ, 145 p, 2010.

[13] ASSOCIAÇÃO BRASILEIRA DE NORMAS TÉCNICAS. NBR 15270-1:2017 - Componentes cerâmicos - Parte 1: Blocos cerâmicos para alvenaria de vedação. Terminologia e requisitos. Rio de Janeiro.

[14] VIEIRA, C. M. F., MONTEIRO, S. N. Effect of the particle size of the grog on the properties of bricks. In: TMS (The Minerals, Metals \& Materials Society), n. 249-254, 2009.

[15] SANTOS, I. S. S., SILVA, N. I. W. Manual de Cerâmica Vermelha. Porto Alegre, SEBRAE/RS. 56 p., 1995.

[16] VIEIRA, C. M. F., SOUZA, E. T. A., MONTEIRO, S. N. "Efeito da incorporação de chamote no processamento e microestrutura de cerâmica vermelha", Cerâmica Industrial Ceramics, n 50, pp. 254-260. 2004.

[17] ASSOCIAÇÃO BRASILEIRA DE NORMAS TÉCNICAS . NBR 15270-1:2005 - Componentes cerâmicos - Parte 1: Blocos cerâmicos para alvenaria de vedação. Terminologia e requisitos. Rio de Janeiro.

[18] CANDIDO, V. S., PINHEIRO, R. M., MONTEIRO, S. N., et al., "Desenvolvimento de adoquim cerâmico com argilas cauliníticas, chamote e argilito", Revista Cerâmica, v.59, n. 310-316, Rio de Janeiro, 2013.

[19] VIEIRA, C. M. F., MONTEIRO, S. N. "Effect of grog addition on the properties and microstructure of a red ceramic body for brick production", Construction and Building Materials, v. 21, pp. 1754-1759, 2007.

[20] VIEIRA, C. M. F., SOARES, J. B., MONTEIRO, S. N. "Desenvolvimento de massas de revestimento cerâmico com argila caulinítica e nefelina sienito", Revista Cerâmica, n. 54, pp. 184-192, 2008.

\section{ORCID}

Lêda de Azevedo Racanelli Verônica Scarpini Cândido José Antônio da Silva Souza Dilson Nazareno Cardoso https://orcid.org/0000-0002-0422-6803 https://orcid.org/0000-0002-3926-0403 https://orcid.org/0000-0002-1784-9217 https://orcid.org/0000-0003-1133-0243 